\title{
Study of Silicon Nanocrystals Formation in Annealed Amorphous In Situ Nitrogen Doped Silicon Thin Films Obtained by Low Pressure Chemical Vapor Deposition
}

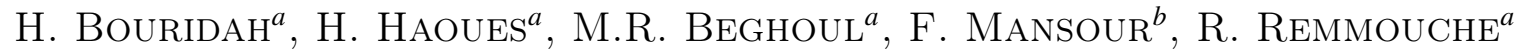 \\ AND P. TEMPLE-BOYER ${ }^{c, d}$ \\ ${ }^{a}$ Département d'Electronique, Université de Jijel, B.P. 98, Ouled Aissa, Jijel 18000, Algeria \\ ${ }^{b}$ Département d'Electronique, Université Mentouri, Route d'Ain El-Bey, Constantine 25000, Algeria \\ ${ }^{c}$ CNRS, LAAS, 7 av. du colonel Roche, F-31077 Toulouse, France \\ ${ }^{d}$ UPS, INSA, INP, ISAE, LAAS, Université de Toulouse, F-31077 Toulouse, France
}

\begin{abstract}
In this work, we investigate the formation of silicon nanocrystals in annealed low pressure chemical vapor deposition in situ nitrogen doped silicon thin films $\left(\mathrm{SiN}_{x}\right)$ obtained at low temperature $\left(465^{\circ} \mathrm{C}\right)$ by using a mixture of disilane $\left(\mathrm{Si}_{2} \mathrm{H}_{6}\right)$ and ammonia $\left(\mathrm{NH}_{3}\right)$. Results show that nitrogen content in films plays an important role in defining the obtained films morphology in terms of crystallites sizes and their distribution. Indeed, according to the nitrogen content introduced in films, the crystalline state of films varies from a submicron crystalline structure to a nanocrystalline structure. An average silicon nanocrystalline size of $10 \mathrm{~nm}$ was obtained for film with $x=0.07$ nitrogen content, annealed under a temperature of $850^{\circ} \mathrm{C}$ during $2 \mathrm{~h}$.
\end{abstract}

PACS: 68.55.ag, 68.55.J-, 61.46.Hk, 81.07.Bc

\section{Introduction}

In the last years, silicon nanocrystals (Si-nc) have attracted a great attention due to the potentiality of Si-nc in nanoelectronic applications such as channel layer of thin films transistor leading to a great enhancement in carrier mobility [1], and in optoelectronic applications, because nc-Si is expected to exhibit a quantum size effect. Several methods tried to form silicon nanocrystals in silicon based materials [2-4]. Indeed, Si-nc is a mixed phase material consisting of nanocrystals of silicon embedded within an amorphous silicon matrix. In this work, we deal to produce silicon nanocrystals by annealing in situ nitrogen doped silicon thin films obtained by low pressure chemical vapor deposition (LPCVD) using a mixture between disilane $\left(\mathrm{Si}_{2} \mathrm{H}_{6}\right)$ and ammonia $\left(\mathrm{NH}_{3}\right)$. LPCVD is widely used in metal oxide semiconductor (MOS) processing line and warrants a high efficiency and a good uniformity of thickness. Disilane and ammonia gas mixture offers the possibility to realize different types of materials between the silicon nitride and amorphous silicon, and hence it is possible to introduce low nitrogen content necessary to obtain high silicon crystallites concentration with smaller sizes. Indeed, the excess of silicon in films allows high silicon crystallites concentration while the nitrogen presence prevents their growth. The interest in using disilane $\mathrm{Si}_{2} \mathrm{H}_{6}$ is related to the introduction of a large amount of silylene $\mathrm{SiH}_{2}$ species into the gaseous phase which are very reactive, allowing deposits at very low temperatures $\left(420-520^{\circ} \mathrm{C}\right)$; i.e. lower than the silicon crystallization temperature $\left(\approx 580^{\circ} \mathrm{C}\right)$ with a high deposition rates [5]. Therefore, it is possible to separate the deposition and the crystallization phenomena.

We investigate the formation of silicon nanocrystals and their size distribution after heat treatment according to the nitrogen content introduced during the films deposit.

\section{Experiment}

Growth experiments were carried out in a conventional hot-wall, horizontal, LPCVD furnace. Thin films with a thickness around $200 \mathrm{~nm}$ were deposited on (111) oxidized (around $120 \mathrm{~nm}$ thermal oxide) silicon substrate, by using a mixture of two gaseous sources, i.e. disilane $\mathrm{Si}_{2} \mathrm{H}_{6}$ and ammonia $\mathrm{NH}_{3}$. The deposition temperature $T$ and the total pressure $P$ were, respectively, fixed to $465^{\circ} \mathrm{C}$ and 200 mTorr. The nitrogen ratio $x=\mathrm{N} / \mathrm{Si}$ and film thickness have been assessed by ellipsometry and checked by profilometry and energy dispersive X-ray (EDX) analysis. Thermal annealing process was performed at a temperature of $850^{\circ} \mathrm{C}$ during $2 \mathrm{~h}$ in a conventional furnace under nitrogen $\left(\mathrm{N}_{2}\right)$ ambient.

The Fourier transform infrared (FTIR) spectroscopy measurements were carried out with a SHIMADZU FTIR 84005 apparatus. Monocrystalline silicon substrate was 
used as background sample and its spectrum is subtracted during the films analysis. Scanning electron microscopic (SEM) images were obtained on a XL-30 microscope equipped with an EDX spectrometer. To be able to visualize the silicon crystals using SEM observation, it is necessary to carry out a SECCO chemical attack that preferentially etches the amorphous matrix of silicon and thus reveals in bright the silicon clusters. The grains size distribution is determined by computer aided image analysis.

\section{Results and discussion}

Figures 1 and 2 report, respectively, the SEM images of films with various nitrogen contents and their corresponding grains size distributions (GSD).

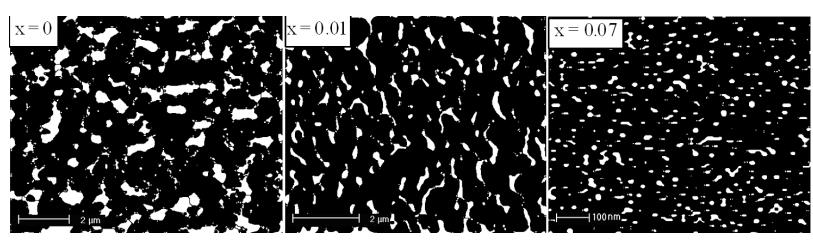

Fig. 1. SEM micrographs for films annealed at $850^{\circ} \mathrm{C} / 2 \mathrm{~h}$ with various nitrogen contents.

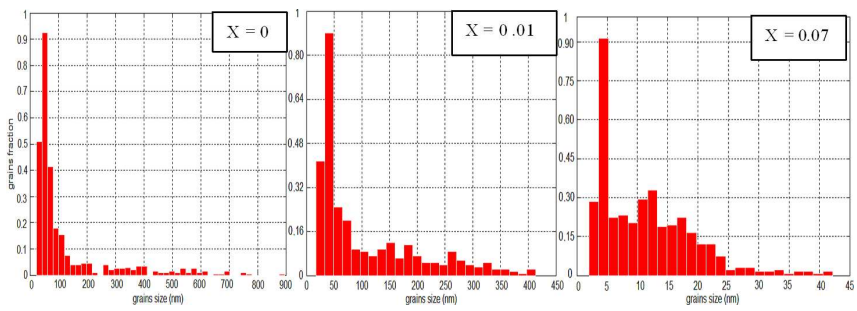

Fig. 2. Histograms of grains size distribution of films annealed at $850^{\circ} \mathrm{C} / 2 \mathrm{~h}$ with various nitrogen contents.

SEM images analysis indicate that the highest silicon crystals density is distributed in size between 43 and $61 \mathrm{~nm}$ for film without nitrogen doping, between 33 and $49 \mathrm{~nm}$ for film with $x=0.01$ nitrogen content, and between 3 and $5 \mathrm{~nm}$ when nitrogen content increases to 0.07 . The largest size of silicon crystallites measured, passes from $900 \mathrm{~nm}$ for film without nitrogen to $42 \mathrm{~nm}$ for film with $x=0.07$ nitrogen content. The variation of the average grain sizes values (deduced from the experimental GSD) as a function of nitrogen tenor (Fig. 3) shows clearly a decrease in the silicon crystallites size with the increase of nitrogen content. A slight decrease in crystallites size values is observed for nitrogen content between 0 and 0.01 . Then, it decreases in a fast way to reach $10 \mathrm{~nm}$ for $x=0.07$ nitrogen content.

On the other hand, a shift toward the large sizes combined with an enlargement of GSD when nitrogen content decreases, can be clearly observed in Fig. 4. Thus, the

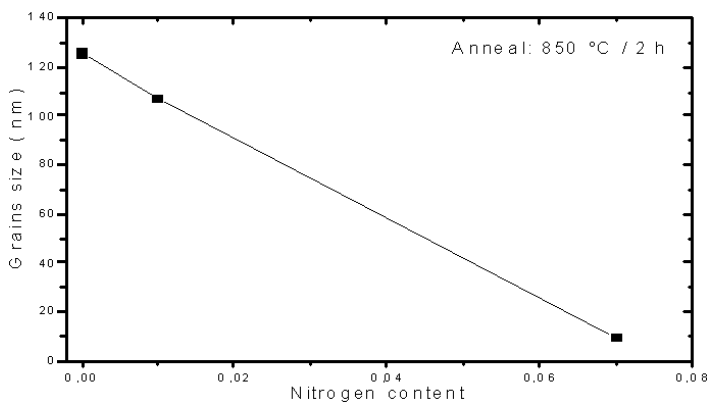

Fig. 3. Average grains size variation as a function of nitrogen content.

crystalline state of films varies from a submicron crystalline structure to a nanocrystalline structure according to the nitrogen level doping.

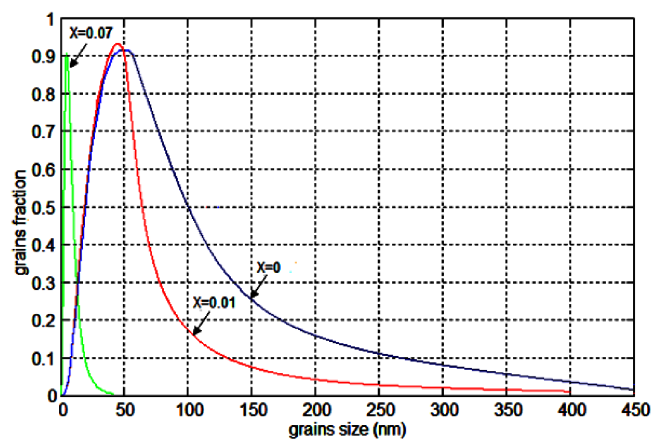

Fig. 4. Comparison between grains size distributions of films annealed at $850^{\circ} \mathrm{C} / 2 \mathrm{~h}$ with various nitrogen contents.

From all these results, it appears clearly that the nitrogen atoms played a key role in the formation of silicon nanocrystals, on the one hand, and in defining their sizes, on the other hand.

Indeed, it was reported [4] that the presence of strong $\mathrm{Si}-\mathrm{N}$ bonds prevented the coalescence of smaller silicon crystals into larger crystallites. To evidence this result, FTIR analysis were carried out.

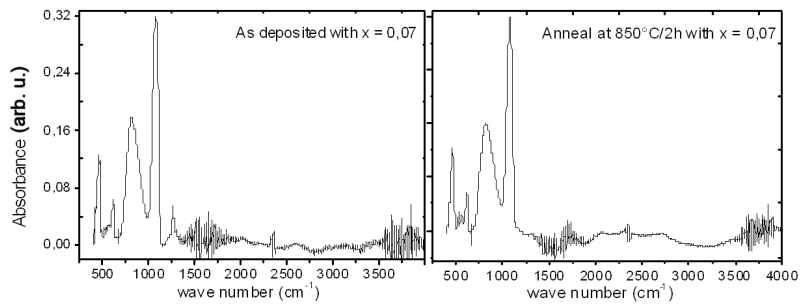

Fig. 5. FTIR absorbance spectra for an as-deposited sample and an annealed sample.

FTIR absorbance spectrum of the as deposited and the annealed sample with nitrogen content of $x=0.07$ is shown in Fig. 5. The peaks centered at 460 and 
$1080 \mathrm{~cm}^{-1}$, known to be for the stoichiometric $\mathrm{SiO}_{2}$, are attributed to the $\mathrm{Si}-\mathrm{O}$ rocking vibration and $\mathrm{Si}-\mathrm{O}-\mathrm{Si}$ stretching vibration, respectively, in the $120 \mathrm{~nm} \mathrm{SiO}_{2}$ interlayer. For the $200 \mathrm{~nm}$ thin film, the bands at 616 , 820 , and $1250 \mathrm{~cm}^{-1}$ can be attributed to $\mathrm{Si}-\mathrm{Si}$ stretching mode, $\mathrm{Si}-\mathrm{N}$ stretching mode, and $\mathrm{Si}-\mathrm{N}-\mathrm{H}$ bending mode, respectively. The absence of the $\mathrm{Si}-\mathrm{N}-\mathrm{H}$ bond in the annealed film is due to the outdiffusion of hydrogen during the heat treatment. The fact that the $\mathrm{Si}-\mathrm{N}$ peak was found centered at about $820 \mathrm{~cm}^{-1}$ instead of the $850 \mathrm{~cm}^{-1}$ (typically attributed to the $\mathrm{Si}-\mathrm{N}$ stretching peak in $\mathrm{Si}_{3} \mathrm{~N}_{4}$ ), is due to the presence of silicon excess in films, i.e. film with low nitrogen content as we can clearly observe in the EDX spectrum of Fig. 6.

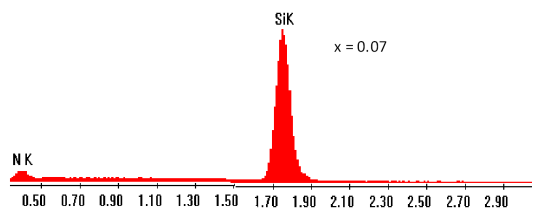

Fig. 6. EDX spectrum for an as-deposited sample.

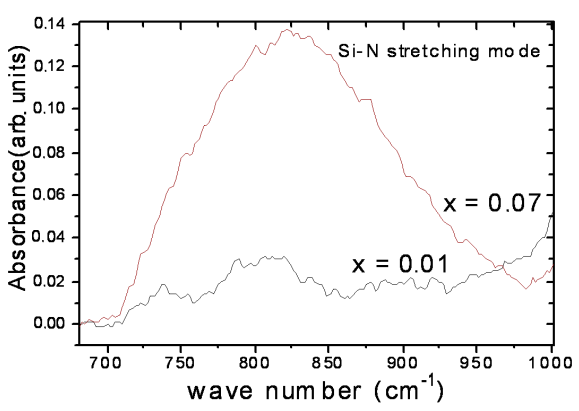

Fig. 7. FTIR absorbance spectra for an as-deposited sample.

We show in Fig. 7 the evolution of the $\mathrm{Si}-\mathrm{N}$ band absorption according to the nitrogen content in the as de- posited films. It is clear that the presence of $\mathrm{Si}-\mathrm{N}$ bond is more relevant for film containing the highest amount of nitrogen. Indeed, when nitrogen atoms are more incorporated during the film deposit process, the density of $\mathrm{Si}-\mathrm{N}$ bonds increases and thus manages to prevent the coalescence between the silicon crystals during the heat treatment.

\section{Conclusion}

We have investigated via this work the formation of silicon nanocrystals in the annealed nitrogen doped silicon thin films. The SEM data analysis of samples with various nitrogen contents annealed at $850{ }^{\circ} \mathrm{C}$ indicated that the silicon grains size distributions are strongly related to the nitrogen level doping. Indeed, it was observed that the silicon crystallites size tends to decrease with the increase of the nitrogen content in films. The presence of $\mathrm{Si}-\mathrm{N}$ bond in films, revealed by FTIR analysis, prevented the coalescence of smaller silicon particles responsible of the obtaining of larger silicon crystallites, leading to a nanocrystalline structure with an average crystallite size depending on the quantity of nitrogen in films.

\section{References}

[1] I.Y.Y. Bu, A.J. Flewitt, W.I. Milne, Curr. Appl. Phys. 11, 171 (2011).

[2] N. Dandosso, G. Das, S. Larcheri, G. Mariotto, G. Dalba, L. Pavesi, A. Irrera, F. Priolo, F. Lacona, F. Rocca, J. Appl. Phys. 101, 113510 (2007).

[3] A.M. Funde, N.A. Bakr, D.K. Kamble, R.R. Hawaldar, D.P. Amalnerkar, S.R. Jadkar, Solar Energy Mater. Solar Cells 92, 1217 (2008).

[4] S. Kohli, J.A. Theil, P.C. Dippo, K.M. Jones, M.M. Al-Jassim, R.K. Ahrenkiel, C.D. Rithner, P.K. Dorhout, Nanotechnology 15, 1831 (2004).

[5] P. Temple-Boyer, B. Rousset, E. Scheid, Thin Solid Films 518, 6897 (2010). 